Communications in Physics, Vol. 30, No. 2 (2020), pp. 133-141

DOI:10.15625/0868-3166/30/2/14657

\title{
USING SOLVENT VAPOR ANNEALING FOR THE ENHANCEMENT OF THE STABILITY AND EFFICIENCY OF MONOLITHIC HOLE-CONDUCTOR-FREE PEROVSKITE SOLAR CELLS
}

\author{
THACH THI DAO LIEN ${ }^{1}$, PHAM VAN PHUC ${ }^{2}$, NGUYEN THI TU OANH ${ }^{2}$, \\ NGUYEN SI HIEU ${ }^{2}$, TA NGOC BACH ${ }^{2}$, PHAM DUY LONG ${ }^{2}$, \\ PHAM VAN $\mathrm{HOI}^{2}$ AND LE HA CHI ${ }^{2, \dagger}$ \\ ${ }^{1}$ Graduate University of Science and Technology, Vietnam Academy of Science and Technology, \\ 18 Hoang Quoc Viet, Cau Giay, Hanoi, Vietnam \\ ${ }^{2}$ Institute of Materials Science, Vietnam Academy of Science and Technology, \\ 18 Hoang Quoc Viet, Cau Giay, Hanoi, Vietnam \\ ${ }^{\dagger} E$-mail: chilh@ims.vast.ac.vn \\ Received 1 December 2019 \\ Accepted for publication 18 February 2020
}

Published 11 May 2020

\begin{abstract}
In the last few years, perovskite solar cells have attracted enormous interest in the photovoltaic community due to their low cost of materials, tunable band gap, excellent photovoltaic properties and easy process ability at low temperature. In this work, we fabricated hole-conductorfree carbon-based perovskite solar cells with the monolithic structure: glass/FTO/bl-TiO $2 /(m p-$ $\mathrm{TiO}_{2} / \mathrm{mp}-\mathrm{ZrO} \mathrm{O}_{2} / \mathrm{mp}$-carbon) perovskite. The mixed $2 \mathrm{D} / 3 \mathrm{D}$ perovskite precursor solution composed of $\mathrm{PbI}_{2}$, methylammonium iodide (MAI), and 5-ammoniumvaleric acid iodide (5-AVAI) was dropcasted through triple mesoporous $\mathrm{TiO}_{2} / \mathrm{ZrO}_{2} /$ carbon electrode films. We found that the isopropyl alcohol (IPA) solvent vapor annealing strongly influenced on the growth of mixed 2D/3D perovskite on triple mesoscopic layers. It resulted in the better pore filling, better crystalline quality of perovskite layer, thus the improved stability and efficiency of perovskite solar cell was attributed to lower defect concentration and reduced recombination.
\end{abstract}

Keywords: perovskite solar cells; monolithic; hole-conductor-free; mixed 2D/3D perovskite; solvent vapor annealing.

Classification numbers: 81.07.Bc; 81.10.Dn; 82.33.Pt; 84.60.Jt.

(C)2020 Vietnam Academy of Science and Technology 


\section{INTRODUCTION}

Solar energy is considered as the largest renewable energy source and may be harnessed for electricity generation using photovoltaic cells. Until now, silicon solar cells are still the most common commercial products used to convert solar energy into electricity. However, the cost of silicon solar cells is still high due to its sophisticated manufacturing technology. Low cost solar cells such as dye sensitized solar cells (DSSCs) [1,2], organic solar cells (OSCs) [3], quantum dots solar cells (QDSCs) [4,5], perovskite solar cells (PSCs) [6] are showing great potential for replacing silicon solar cells. Among these cells, perovskite solar cells (PSCs) have recently emerged as a rising photovoltaic technology due to their outstanding optoelectronic properties cost effective and low-temperature solution-processable fabrication techniques [7]. The rapid increase in their power conversion efficiency (PCE) from 3.8\% to $25.2 \%$ in only a few years has made perovskite solar cells becoming an attractive field of study for the scientific community [8-10]. Although the impressive power conversion efficiencies have been achieved with small-area laboratory-scale cells, perovskite solar cells still remain challenges from the scalability and long-term operational instability [11]. Moreover, using the organic hole transport materials (HTMs) and rare metals as back contact, such as gold and silver, may limit large-scale perovskite solar cell production due to their expensive materials and complicated fabrication procedure [12]. A promising way to solve the above problems of PSCs is replacing carbon-based electrodes for HTMs and Au electrodes [13]. The advantages of carbon-based perovskite solar cells without HTMs are cost effective, stable and suitable for large-scale commercialization $[13,14]$. There are mainly two types of device configurations in carbon-based perovskite solar cells including: the conventional structure fabricated by a layer-by-layer process and the monolithic structure featured by the loading of perovskite in the last step $[14,15]$. Among these carbon-based PSCs, the monolithic structure provides a simplified fabrication process to solar cell modules [16]. In this work, we fabricated hole-conductorfree carbon-based perovskite solar cells with the monolithic structure of glass/FTO/bl- $\mathrm{TiO}_{2} /(\mathrm{mp}-$ $\mathrm{TiO}_{2} / \mathrm{mp}-\mathrm{ZrO}_{2} / \mathrm{mp}$-carbon)perovskite. A one-step infiltration process with the mixed $2 \mathrm{D} / 3 \mathrm{D}$ perovskite precursor solution of $\mathrm{PbI}_{2}$, methylammonium iodide (MAI), and 5-ammoniumvaleric acid iodide (5-AVAI) through triple mesoporous $\mathrm{TiO}_{2} / \mathrm{ZrO}_{2} /$ carbon electrode films was investigated. The isopropyl alcohol (IPA) solvent vapor annealing method was used to improve device performance of those hole-conductor-free carbon-based perovskite solar cells. This specific strategy for achieving enhanced-performance and stable perovskite solar cells will be discussed with an aim to develop the promising technology for commercialization.

\section{EXPERIMENT}

Fabrication of mixed 2D/3D perovskite precursor solution: lead iodide $\left(\mathrm{PbI}_{2}\right)$, methylammonium iodide (MAI), 5-ammoniumvaleric acid iodide (5-AVAI) with $3 \%$ of molar ratio between 5-AVAI and MAI were mixed thoroughly and dissolved in $2 \mathrm{ml}$ gamma-butyrolactone (GBL) solvent to obtain the mixed 2D/3D (5-AVA) $)_{x}(\mathrm{MA})_{1-x} \mathrm{PbI}_{3}$ perovskite precursor solution.

Device fabrication: In this work, we prepared the monolithic hole-conductor-free perovskite solar cell with device configuration of glass/FTO/bl- $\mathrm{TiO}_{2} /\left(\mathrm{mp}-\mathrm{TiO}_{2} / \mathrm{mp}-\mathrm{ZrO}_{2} /\right.$ mp-carbon)/perovskite Firstly, the FTO glass substrates were chemically etched by solution $\mathrm{HCl}$ $2 \mathrm{M}$ and $\mathrm{Zn}$ powder to obtain the designed electrode. They were ultrasonically cleaned by ethanol, acetone, deionized water and then dried at $110^{\circ} \mathrm{C}$. A blocking titania paste was screen-printed onto 


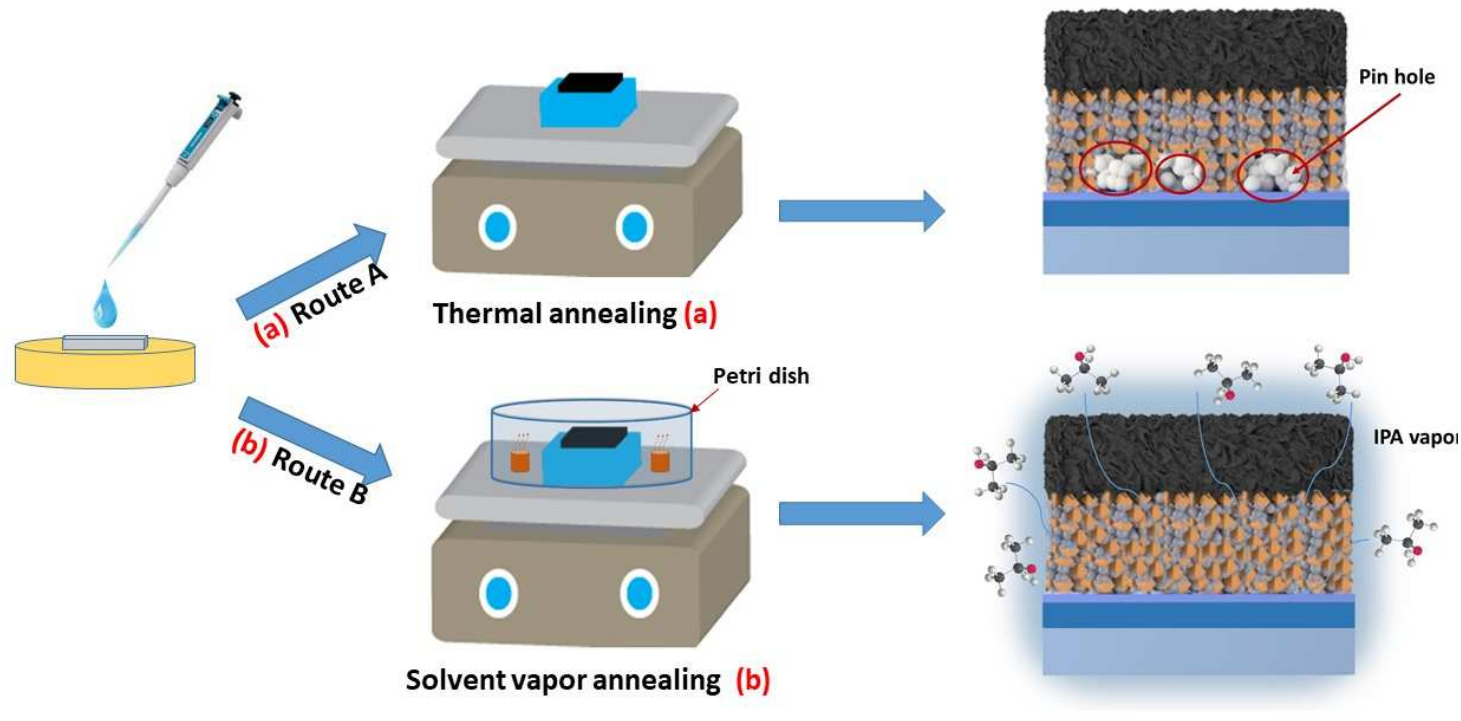

Fig. 1. Schematic illustrations of the experimental setup for the conventional thermal annealing (a) and the solvent vapor annealing using a petri dish (b).

the cleaned FTO substrate by using a 120 polyester mesh screen and then annealed in air condition at $450^{\circ} \mathrm{C}$ for an hour to obtain an ultra-thin, dense and pinhole-free $\mathrm{TiO}_{2}$ blocking layer (bl- $\left.\mathrm{TiO}_{2}\right)$ Then, a scafffolding titania paste containing $\mathrm{TiO}_{2}$ anatase nanoparticles (average diameter $\sim 18$ $\mathrm{nm}$ ) was spread on the $\mathrm{bl}_{-}-\mathrm{TiO}_{2}$ layer using the screen printing method with a 80 polyester mesh screen and annealed at $500^{\circ} \mathrm{C}$ for 30 minutes to produce a mesoporous $\mathrm{TiO}_{2}$ layer $\left(\mathrm{mp}-\mathrm{TiO}_{2}\right)$. The same technique was applied for $\mathrm{ZrO}_{2}$ nanoparticle paste to obtain a mesoporous $\mathrm{ZrO}_{2}$ layer (mp$\mathrm{ZrO}_{2}$ ). The $\mathrm{mp}-\mathrm{ZrO}_{2}$ film serves as a spacer layer to avoid any direct contact between the mp-TiO film and $\mathrm{mp}$-carbon film. To prepare carbon paste, $9 \mathrm{~g}$ of graphite powder, $3 \mathrm{~g}$ of carbon black, 1.2 $\mathrm{g}$ of poly-vinyl-difluoride (PVdF 6020 Solvay Solef) and $18 \mathrm{~g}$ terpineol were mixed thoroughly in a mortar. Then absolute ethanol was gradually added to the mixture while continuously magnetic stirring until a smooth slurry of carbon paste was obtained. Carbon paste was doctor-bladed on the top mp- $\mathrm{ZrO}_{2}$ layer and consequently sintered at $400^{\circ} \mathrm{C}$ for 30 minutes to complete a mesoporous carbon counter electrode layer. The active area of the cell was $1.2 \mathrm{~cm}^{2}$. To complete the device, the $(5-\mathrm{AVA})_{x}(\mathrm{MA})_{1-x} \mathrm{PbI}_{3}$ perovskite precursor solution was dropped on the top of the carbon electrode to infiltrate through the triple mesoporous layer (mp- $\mathrm{TiO}_{2} / \mathrm{mp}-\mathrm{ZrO} \mathrm{Z}_{2} / \mathrm{mp}$-carbon) for 20 minutes Then, the device A was heated on the hot plate at $50^{\circ} \mathrm{C}$ for 4 hours in ambient air for the conventional thermal annealing method (TA) in route A. For the device B treated with the solvent vapor annealing method (SA) in route B, isopropyl alcohol (IPA) was dropped and covered with a Petri dish to form the IPA vapor atmosphere. The processing scheme illustrated the experimental setup for the conventional thermal annealing and the solvent vapor annealing using a petri dish as shown in Fig. 1. Finally, our encapsulated devices were sealed together with thermal melt polymer film (Meltonix 1170-60, 60 $\mathrm{m}$ thick) and covered on top with glass substrate by 
using hot-pressing machine at $120^{\circ} \mathrm{C}$ for 5 minutes. All the above processing procedures were completed in ambient air condition.

Materials and device characterization: The morphology of samples was studied by using a Hitachi S-4800 field emission scanning electron microscopy (FE-SEM). The crystalline characterization was identified by a Bruker D8-Advance X-ray diffractometer $(\mathrm{CuK} \alpha$ as radiation source, $\lambda=1.5406 \AA$ ). The absorption spectra were performed by using a Shimadzu 2600 UV-Vis-NIR spectrometer. Photocurrent density-voltage (J-V) curves were recorded by a Keithley 2400 source under AM1.5G simulated solar illumination with light intensity of one sun $\left(100 \mathrm{~mW} / \mathrm{cm}^{2}\right)$ by

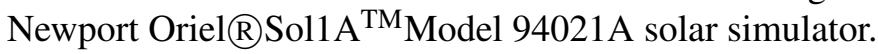

\section{RESULTS AND DISCUSSION}

The FE-SEM images in Fig. 2 show the cross-sectional structure of monolithic holeconductor-free perovskite solar cells. As can be seen in Fig. 2 a and b, the unfilled perovskite
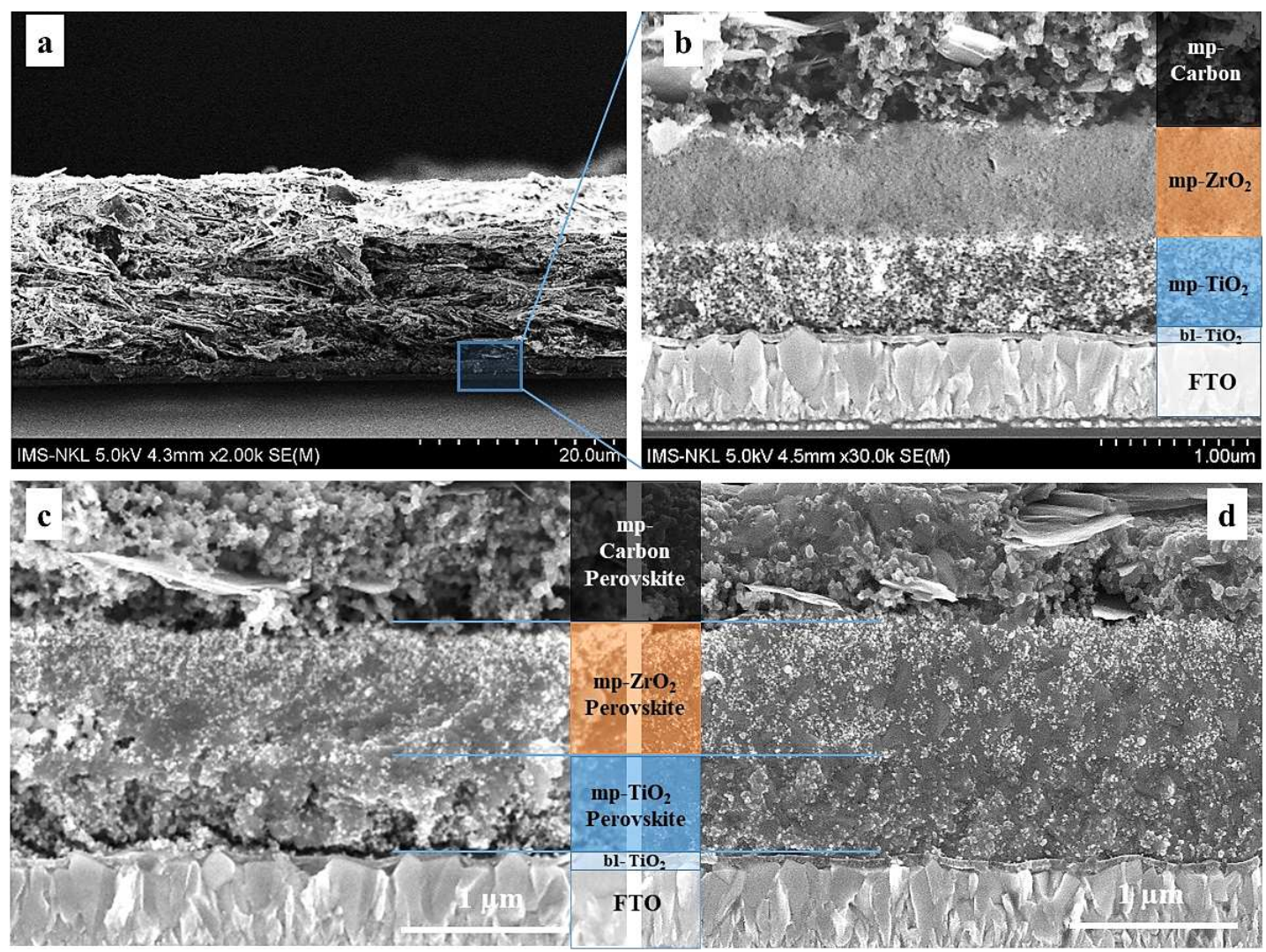

Fig. 2. Cross-sectional FESEM images of monolithic hole-conductor-free perovskite solar cell: the unfilled perovskite device with the structure of glass/FTO/bl- $\mathrm{TiO}_{2} / \mathrm{mp}-\mathrm{TiO}_{2} / \mathrm{mp}$ $\mathrm{ZrO}_{2} / \mathrm{mp}$-carbon electrode at two different resolutions $(\mathrm{a}, \mathrm{b})$ and the filled perovskite devices with the structure of glass/FTO/bl- $\mathrm{TiO}_{2} /\left(\mathrm{mp}-\mathrm{TiO}_{2} / \mathrm{mp}-\mathrm{ZrO}_{2} / \mathrm{mp}\right.$-carbon)/perovskite after conventional thermal treatment (c) and solvent annealing treatment (d). 
device displays the layered structure of glass/FTO/bl- $\mathrm{TiO}_{2} / \mathrm{mp}-\mathrm{TiO}_{2} / \mathrm{mp}-\mathrm{ZrO}_{2} / \mathrm{mp}$-carbon electrode. The thickness of each layer was about $50 \mathrm{~nm}$ of bl- $\mathrm{TiO}_{2}, 600 \mathrm{~nm}$ of mp- $\mathrm{TiO}_{2}, 750 \mathrm{~nm}$ of $\mathrm{mp}-\mathrm{ZrO}_{2}$ and $18 \mu \mathrm{m}$ of mp-carbon, correspondingly. The loading content of the mixed 2D/3D perovskite in $\mathrm{TiO}_{2} / \mathrm{ZrO}_{2}$ scaffold layers using conventional thermal annealing treatment (route $\mathrm{A}$ ) and solvent annealing treatment (route B) can be seen in the cross-sectional FE-SEM images of devices, as shown in Fig. $2 \mathrm{c}$ and d. From the morphological observation, the device A treated with conventional thermal annealing remains some non-infiltrated mesopores (pin-holes). While the device B treated with solvent annealing showed better pores filling and homogenous perovskite film morphology loading on the mesopores of the $\mathrm{TiO}_{2}$ and $\mathrm{ZrO}_{2}$ scaffold. It is found that the solvent annealing treatment results in the better morphology related to characteristics of nucleation and growth process $[17,18]$.

As shown in Fig. 3, X-ray diffraction (XRD) measurements were taken to identify the crystal structure of the $2 \mathrm{D} / 3 \mathrm{D}$ mixed (5-AVA) ${ }_{x}(\mathrm{MA})_{1-x} \mathrm{PbI}_{3}$ perovskites coated on substrate glass $/ \mathrm{FTO} / \mathrm{bl}-\mathrm{TiO}_{2} / \mathrm{mp}-\mathrm{TiO}_{2} / \mathrm{mp}-\mathrm{ZrO}_{2}$ using the conventional thermal annealing treatment (TA) and the solvent vapor annealing treatment (SA). The XRD patterns of both samples exhibited strong diffraction peaks of (110), (220) and (310) and some minor peaks of (112), (111), (202), (224), and (314). It is noted that the intensity of the (110), (220) and (310) peaks of the solvent annealing treated perovskite film were higher than the same peaks of the thermal annealing treated perovskite film. The obtained results indicated that perovskite crystallinity and preferred orientation can be increased by solvent vapor annealing treatment.

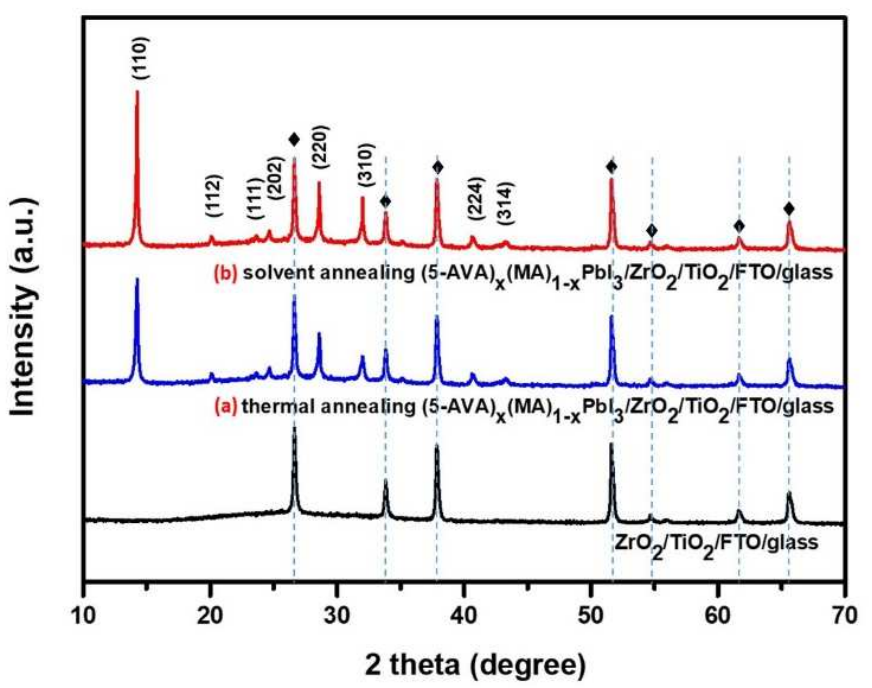

Fig. 3. XRD patterns of $(5-\mathrm{AVA})_{x}(\mathrm{MA})_{1-x} \mathrm{PbI}_{3}$ perovskite films coated on substrate glass/FTO/bl- $\mathrm{TiO}_{2} / \mathrm{mp}-\mathrm{TiO}_{2} / \mathrm{mp}-\mathrm{ZrO}_{2}$ with the conventional thermal annealing treatment (a) and the solvent vapor annealing treatment (b).

The optical properties of 2D/3D mixed (5-AVA) $)_{x}(\mathrm{MA})_{1-x} \mathrm{PbI}_{3}$ perovskites prepared using thermal annealing (TA) and solvent vapor annealing (SA) were investigated by the 
UV-Vis spectroscopy. The results shown in Fig. 4 indicated that both the TA and SA treated (5-AVA $)_{x}(\mathrm{MA})_{1-x} \mathrm{PbI}_{3}$ perovskites exhibited excellent light-harvesting capabilities in the broad spectral range from the ultraviolet to visible light. We observed similar absorption for both samples and clear band edge cutoffs at $776 \mathrm{~nm}$. However, the SA sample show a slight increase in UV-vis absorbance and sharper band edge, which is consistent with higher levels of crystallinity and fewer defect concentration. These results supported that $2 \mathrm{D} / 3 \mathrm{D}$ mixed (5-AVA) $)_{x}(\mathrm{MA})_{1-x} \mathrm{PbI}_{3}$ perovskite can be used as an efficient light-harvester for photovoltaic (PV) applications.

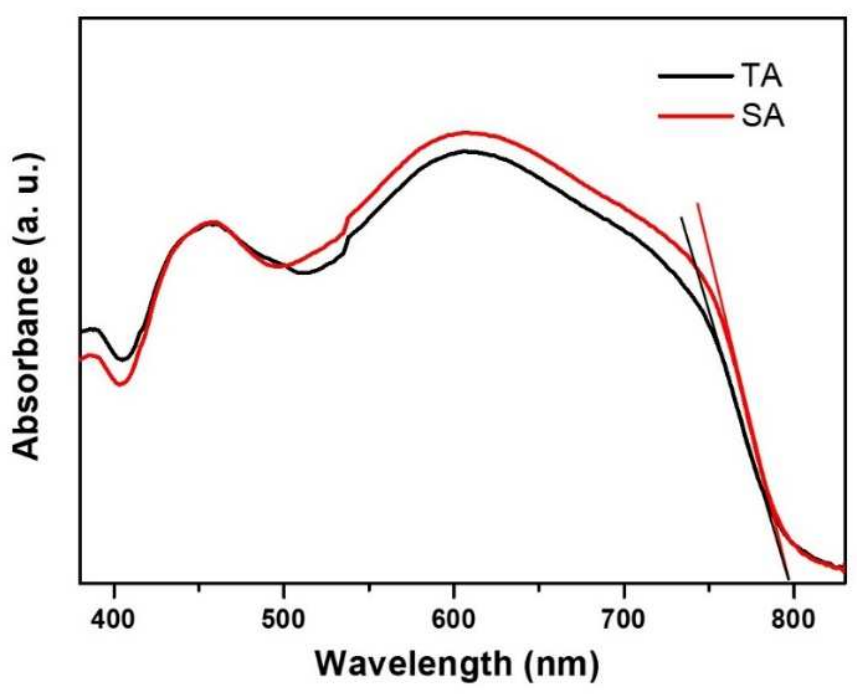

Fig. 4. UV-vis absorption spectra of the mixed (5-AVA) $)_{x}(\mathrm{MA})_{1-x} \mathrm{PbI}_{3}$ perovskites treated by thermal annealing (TA) and solvent vapor annealing (SA) on mp- $\mathrm{TiO}_{2} / \mathrm{bl}$ $\mathrm{TiO}_{2} /$ FTO/glass substrates.

Figure 5 illustrates the schematic drawing of the cross-sectional device architecture (a) and the energy band diagram of the mesoscopic triple-layer perovskite solar cell with the structure of glass/FTO/bl- $\mathrm{TiO}_{2} /\left(\mathrm{mp}-\mathrm{TiO}_{2} / \mathrm{mp}-\mathrm{ZrO}_{2} / \mathrm{mp}\right.$-carbon)/perovskite. The J-V characteristic of the monolithic hole-conductor-free perovskite solar cell using mixed 2D/3D perovskite prepared by thermal annealing (TA) and solvent vapor annealing (SA) were measured as shown in Fig. 6. The photovoltaic parameters of these perovskite solar cells are displayed in Table 1. In our experiment, the best device using mixed 2D/3D perovskite prepared by solvent vapor annealing (SA) was achieved with the following photovoltaic parameters: the open-circuit voltage $\left(V_{o c}\right) 1.04 \mathrm{~V}$, the short-circuit current density $\left(J_{s c}\right) 12.54 \mathrm{~mA} / \mathrm{cm}^{2}$, the fill factor $(\mathrm{FF}) 0.59$, and the power conversion efficiency (PCE) 7.69\%. The $J-V$ curve of SA-device shows that solvent vapor annealing treatment significantly improved the device performance From the above analysis, the solvent vapor annealing treatment resulted in perovskite crystallization with larger grain size, better film coverage grown through mesoscopic triple-layers. It has been widely reported that perovskite thin film morphology and perovskite crystal quality strongly influence on photovoltaic performance of the perovskite solar cells [19-21]. Therefore, the optic-electrical properties of the monolithic 
hole-conductor-free perovskite solar cells could be enhanced due to the solvent vapor annealing treatment. Moreover, the good long-term stability of the SA-based perovskite solar cell was observed as seen in Fig. 7. It was attributed to lower defect concentration and reduced recombination due to the enhanced film morphology of the monolithic hole-conductor-free perovskite solar cell prepared by solvent vapor annealing (SA-device) [22-24]. Our results are in agreement with previous studies reporting that suitable material processing plays an important role for the stability and crystallization of perovskite films $[6,25]$.

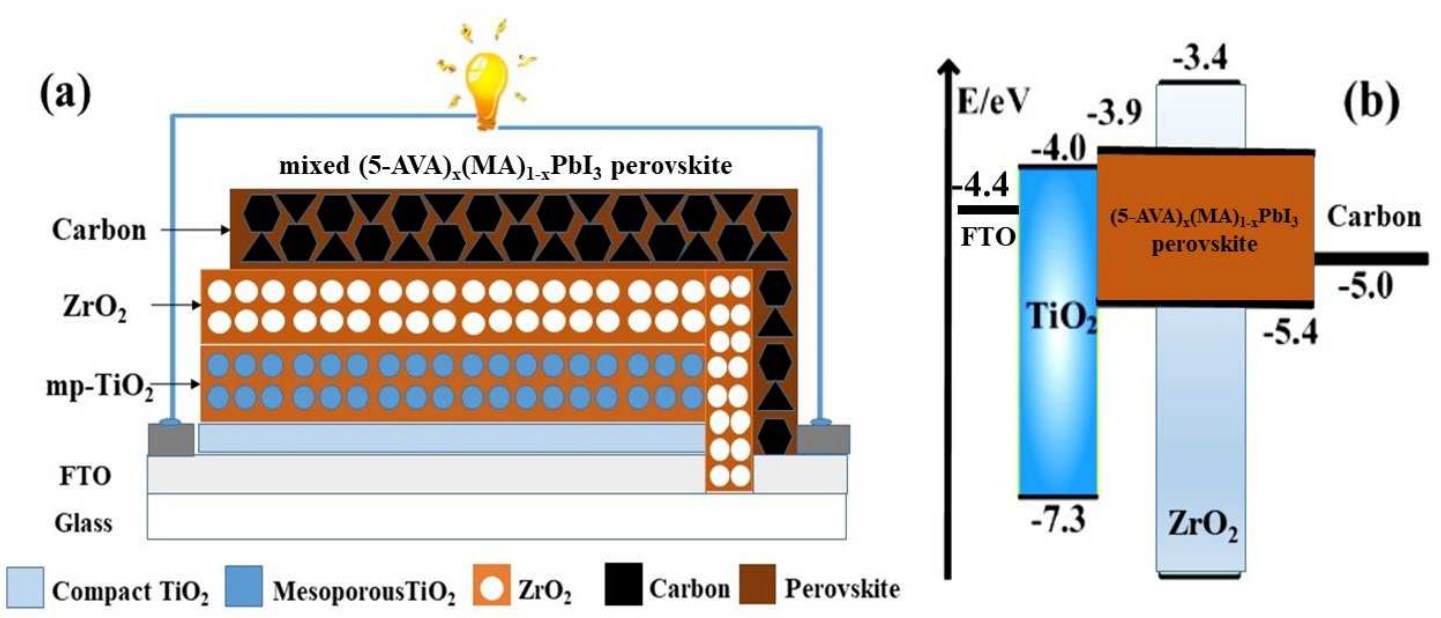

Fig. 5. Device architecture (a) and energy band diagram (b) of monolithic holeconductor-free perovskite solar cell.

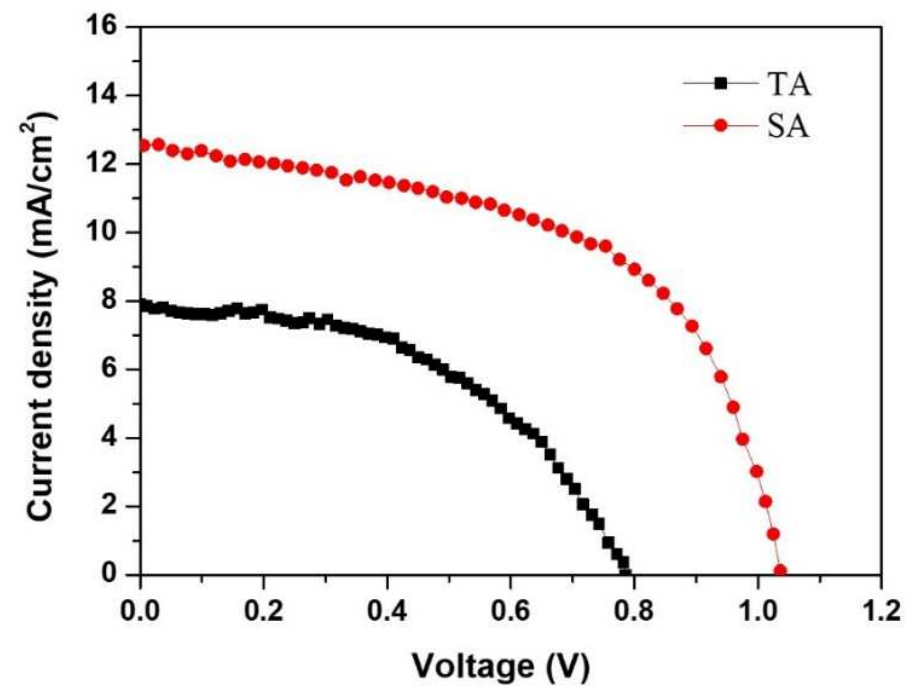

Fig. 6. J-V curves of monolithic hole-conductor-free carbon-based perovskite solar cells prepared using thermal annealing (TA) and solvent vapor annealing (SA). 
Table 1. Photovoltaic parameters of the monolithic hole-conductor-free perovskite solar cell prepared by conventional thermal annealing (TA) and solvent vapor annealing (SA).

\begin{tabular}{ccccc}
\hline Device samples & $\boldsymbol{V}_{o c}(\mathbf{V})$ & $\boldsymbol{J}_{s c}\left(\mathbf{m A} / \mathbf{c m}^{2}\right)$ & $\mathbf{F F}$ & PCE (\%) \\
\hline TA & 0.79 & 7.88 & 0.51 & 317 \\
\hline SA & 104 & 12.54 & 0.59 & 769 \\
\hline
\end{tabular}

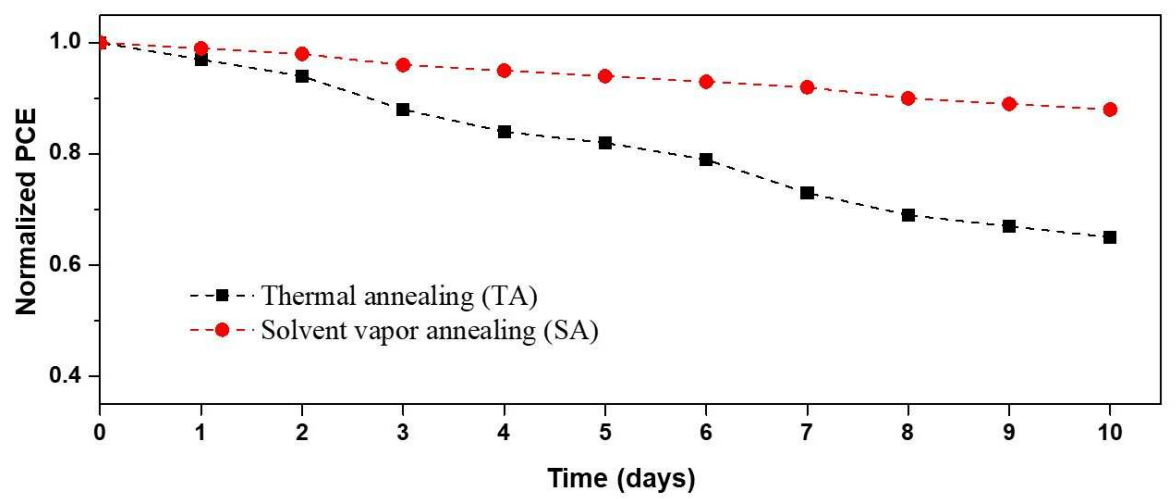

Fig. 7. Long-term stability of the encapsulated monolithic hole-conductor-free carbonbased perovskite solar cells (SA and TA) measured under AM1.5G simulated solar illumination in air.

\section{CONCLUSIONS}

We successfully fabricated the hole-conductor-free carbon-based perovskite solar cell with the monolithic structure of glass/FTO/bl- $\mathrm{TiO}_{2} /\left(\mathrm{mp}-\mathrm{TiO}_{2} / \mathrm{mp}-\mathrm{ZrO}_{2} / \mathrm{mp}\right.$-carbon) perovskite under ambient air condition. The crystallization and properties of the $2 \mathrm{D} / 3 \mathrm{D}$ mixed $(5-\mathrm{AVA})_{x}(\mathrm{MA})_{1-x} \mathrm{PbI}_{3}$ perovskite growing through triple mesoporous $\mathrm{TiO}_{2} / \mathrm{ZrO}_{2} /$ carbon electrode films via thermal annealing (TA) and solvent vapor annealing (SA) were investigated. It was found that the isopropyl alcohol (IPA) solvent vapor annealing treatment could improve perovskite crystallinity, better pores filling and homogenous perovskite film morphology. Therefore, the isopropyl alcohol (IPA) solvent vapor annealing treatment could be applied to increase stability and efficiency of those hole-conductor-free carbon-based perovskite solar cells As a result, the best device using mixed 2D/3D perovskite prepared by solvent vapor annealing (SA) was achieved with the following photovoltaic parameters: $V_{o c}=1.04 \mathrm{~V}, J_{s c}=12.54 \mathrm{~mA} / \mathrm{cm}^{2}, \mathrm{FF}=0.59$, and $\mathrm{PCE}=7.69 \%$. This pave the way for enhancing the stable and low-cost photovoltaic application.

\section{ACKNOWLEDGMENT}

This work is supported by Vietnam Academy of Science and Technology (grant number VAST.03.02/18-19). Pham Duy Long author thanks for the financial support from Vietnam Academy of Science and Technology (grant number NCVCC04.05/19-19). 


\section{REFERENCES}

[1] Z. Ning, Y. Fu and H. Tian, Energy Environ. Sci. 3 (2010) 1170.

[2] L. V. Hong, D. T. Cat, L. H. Chi, N. T. Thuy, Tr. V. Hung, L. N. Tai and P. D. Long, Journal of Electronic Materials 45 (2016) 4833-4837.

[3] H. Choi, J. Lee, C.M. Oh, S. Jang, H. Kim, M. S. Jeong, S. H. Park and I. W. Hwang, J. Mater. Chem. A 7 (2019) 8805.

[4] G. H. Carey, A. L. Abdelhady, Z. Ning, S. M. Thon, O. M. Bakr and E. H. Sargent, Chem. Rev. 115 (2015) 12732.

[5] L. H. Chi, P. D. Long, H.V. Chung, D. T. Phuong, D. X. Mai, N. T. T. Oanh, T. T. D. Lien and L. V. Trung, Appl. Mech. Mater. 618 (2014) 64.

[6] A. Dubey, N. Adhikari, S. Mabrouk, F. Wu, K. Chen, S. Yang and Q. Qiao, J. Mater. Chem. A 6 (2018) 2406.

[7] N. G. Park, Mater. Today 18 (2015) 65.

[8] A. Kojima, K. Teshima, Y. Shirai and T. Miyasaka, Journal of the American Chemical Society, 131 (2009) 6050-6051.

[9] J. P. Correa-Baena, A. Abate, M. Saliba, W. Tress, T. J. Jacobsson, M. Gratzel and A. Hagfeldt, Energy Environ. Sci.10 (2017) 710-727.

[10] S. Shao and M. A. Loi,Adv. Mater. Interfaces (2019) 1901469

[11] W. W. Liu, T. H. Wu, M.C. Liu, W. J. Niu and Y. L. Chueh, Adv. Mater. Interfaces 6 (2019) 1801758.

[12] X. Yang, H. Wang, B. Cai, Z. Yu and L. Sun, J. Energy Chem. 27 (2018) 650.

[13] A. Mei, X. Li, L. Liu, Z. Ku, T. Liu, Y. Rong, M. Xu, M. Hu, J. Chen, Y. Yang, M. Grätzel and H. Han, Science 345 (2014) 295.

[14] Y. Cai, L. Liang and P. Gao, Chinese Phys. B 27 (2018) 018805.

[15] L. Xu, F. Wan, Y. Rong, H. Chen, S. He, X. Xu, G. Liu, H. Han, Y. Yuan, J. Yang, Y.Gao, B. Yang and C. Zhou, Org. Electron. 45 (2017) 131.

[16] Y. Hu, S. Si, A. Mei, Y. Rong, H. Liu, X. Li and H. Han, Solar-RRL 1 (2017) 1600019.

[17] T. Liu, L. Liu, M. Hu, Y. Yang, L. Zhang, A. Mei and H. Han, Journal of Power Sources 293 (2015) 533.

[18] G. E. Eperon, V. M. Burlakov, P. Docampo, A. Goriely and H. J. Snaith, Adv. Func. Mater. 24 (2014) 151.

[19] F. Zhang, J. Song, L. Zhang, F. Niu, Y. Hao, P. Zeng, H. Niu, J. Huang and J. Lian, J. Mater. Chem. A 4 (1) (2016) 8554-8561.

[20] J. Liu, C. Gao, X. He, Q. Ye, L. Ouyang, D. Zhuang, C. Liao, J. Mei and W. Lau, ACS Appl. Mater. Interfaces 7 (43) (2015) 24008.

[21] T Salim, S Sun, Y Abe, A Krishna, A C. Grimsdale,and Y M Lam, J. Mater. Chem. A 3 (2015) 8943.

[22] D. H. Chun, S. Kim, S. U. Chai, W. Kim, W. Kim, J.H. Lee, R. Rhee, D. Choi, J. K. Kim, H. Shin and Jong Hyeok Park, Nano Lett. 19 (9) (2019) 6498.

[23] W. Tress, M. Yavari, K. Domanski, P. K. Yadav, B. Niesen, J. Correa-Baena, A. Hagfeldt and M. Grätzel, Energy \& Environmental Science 11 (2018) 151.

[24] D. W. de Quilettes, S. M. Vorpahl, S. D. Stranks, H. Nagaoka, G. E. Eperon, M. E. Ziffer, H. J. Snaith and D. S. Ginger, Science 348 (2015) 683.

[25] J. Luo, R. Z. Qiu, Z. S. Yang, Y. X. Wang and Q. F. Zhang, RSC Adv. 8 (2018) 724. 